\title{
BMJ Open Safety of ceftriaxone in paediatrics: a systematic review protocol
}

\author{
Linan Zeng, ${ }^{1,2}$ Imti Choonara, ${ }^{3}$ Lingli Zhang, ${ }^{1,2}$ Song Xue, ${ }^{4}$ Zhe Chen, ${ }^{1,2}$ \\ Miaomiao $\mathrm{He}^{4}$
}

To cite: Zeng L, Choonara I, Zhang L, et al. Safety of ceftriaxone in paediatrics: a systematic review protocol. BMJ Open 2017;7:e016273. doi:10.1136/ bmjopen-2017-016273

- Prepublication history and additional material for this paper are available online. To view these files please visit the journal online (http://dx.doi. org/10.1136/bmjopen-2017016273).

Received 3 February 2017 Revised 23 May 2017 Accepted 6 June 2017

\section{CrossMark}

${ }^{1}$ Department of Pharmacy, Evidence-Based Pharmacy Center, West China Second University Hospital, Sichuan University, Chengdu, China ${ }^{2}$ Key Laboratory of Birth Defects and Related Diseases of Women and Children, Sichuan University, Ministry of Education, Chengdu, China

${ }^{3}$ Academic Division of Child Health, University of Nottingham, Derbyshire Children's Hospital, Derby, UK

${ }^{4}$ West China School of Pharmacy, Sichuan University, Chengdu, China

Correspondence to

Dr Lingli Zhang;

zhanglingli@scu.edu.cn

\section{ABSTRACT}

Introduction Ceftriaxone is widely used in children in the treatment of sepsis. However, concerns have been raised about the safety of ceftriaxone, especially in young children. The aim of this review is to systematically evaluate the safety of ceftriaxone in children of all age groups.

Methods and analysis MEDLINE, PubMed, Cochrane Central Register of Controlled Trials, EMBASE, CINAHL, International Pharmaceutical Abstracts and adverse drug reaction (ADR) monitoring systems will be systematically searched for randomised controlled trials (RCTs), cohort studies, case-control studies, cross-sectional studies, case series and case reports evaluating the safety of ceftriaxone in children. The Cochrane risk of bias tool, Newcastle-0ttawa and quality assessment tools developed by the National Institutes of Health will be used for quality assessment. Meta-analysis of the incidence of ADRs from RCTs and prospective studies will be done. Subgroup analyses will be performed for age and dosage regimen.

Ethics and dissemination Formal ethical approval is not required as no primary data are collected. This systematic review will be disseminated through a peer-reviewed publication and at conference meetings.

PROSPERO registration number CRD42017055428.

\section{INTRODUCTION}

Cephalosporins are an important class of antibiotics for the treatment of a wide variety of infections. As a third-generation cephalosporin, ceftriaxone was approved for marketing in the USA in $1984 .^{1}$ Similar to other $\beta$-lactam antibiotics, the antibacterial activity of ceftriaxone results from the inhibition of the bacterial cell wall synthesis. ${ }^{2}$ Since ceftriaxone has a strong antibacterial effect, long half-life and a good curative effect, it is widely used in neonates, infants and children in the treatment of sepsis and meningitis. ${ }^{3-7}$ Nevertheless, concerns have been raised about the safety of ceftriaxone in both adults and children.

The Food and Drug Administration (FDA) issued an alert in 2007, warning that the interaction of ceftriaxone with calcium-containing products may lead to a fatal adverse drug reaction $(\mathrm{ADR})$ in neonates and the potential for this interaction exists in patients

\section{Strengths and limitations of this study}

All types of clinical studies across all paediatric age groups will be included without language limitation.

- Pharmacovigilance databases such as VigiBase (WHO-Uppsala Monitoring Centre) will be searched for suspected adverse drug reactions to ceftriaxone.

- We will follow the Preferred Reporting Items for Systematic Review and Meta-Analysis Protocols and use Cochrane quality assessment tools.

- The systematic review will include only published data.

of any age. ${ }^{8}$ The seriousness of these events, coupled with their preventable nature, has led the FDA and the manufacturer to issue an important warning to the medical community and change the product labelling. ${ }^{9}$ Moreover, a wide range of other ADRs including liver injury have been reported in children and some have been added to the Summary of Product Characteristics (SPC). ${ }^{10-12}$ A weakness of SPC changes, however, is that health professionals are unaware of changes. Our aim is to provide a comprehensive review of safety information for ceftriaxone for paediatric patients. Such a review will be useful for both individual health professionals and groups developing antibiotic guidelines. ${ }^{13}$ Although a few reviews have evaluated ADRs of ceftriaxone in children in a certain system, there is a lack of overall assessment of risk estimates of ceftriaxone ADRs and review of ceftriaxone safety in children. ${ }^{14} 15$ The aim of this review is to systematically evaluate the safety of ceftriaxone in children of all age groups.

\section{SYSTEMATIC REVIEW QUESTIONS}

- What are the rates and categories of ceftriaxone ADRs in children?

- Is there a subgroup of paediatric patients for whom the risk of ceftriaxone ADRs is higher and where other antibiotics may be more appropriate? 


\section{METHODS}

Rigorous methodology will be adopted in this review and will conform to the reporting standards of the Preferred Reporting Items for Systematic Reviews and Meta-analyses. ${ }^{16} 17$ This protocol is registered with the international prospective register of systematic reviews: CRD42017055428.

\section{ELIGIBILITY CRITERIA}

Selection criteria will use the Population, Intervention, Comparison, Outcome, Study design to determine eligibility of articles. No limitation on language and year of publication will be set.

\section{Population}

We will include paediatric patients aged from birth to 18 years and classified according to the International Conference on Harmonisation of Technical Requirements for Registration of Pharmaceuticals for Human Use criteria: preterm newborn infants, term newborn infants $(0-27$ days), infants and toddlers (28 days to 23 months), children (24months to 11 years) and adolescents (12-18 years).${ }^{18}$ There will be no limitation on medical condition or indication.

\section{Intervention}

Ceftriaxone.

\section{Comparison}

Placebo, no intervention or other pharmacological interventions.

\section{Outcome}

The incidence and category of ADRs in paediatric patients. WHO-Uppsala Monitoring Centre system will be adopted to evaluate the relevance of suspected ADRs and ceftriaxone. ${ }^{19}$

\section{Study design}

We will include all types of studies including randomised controlled trial (RCT), cohort study, case-control study, cross-sectional study, case series and case report in the systematic review. Only peer-reviewed publications will be included. The reason for including all study types is that toxicity is poorly reported in RCTs. Previous systematic reviews of toxicity of medicines have always included case series and case reports. ${ }^{20}{ }^{21}$ This will allow a comprehensive evaluation of the safety of ceftriaxone in paediatric patients. Editorials, conference abstracts and reviews will be excluded. Studies evaluating the safety of using ceftriaxone during pregnancy and studies including both children and adults will be excluded if they fail to clearly state the age of patients who experienced ADRs.

We will also review ADR reports from pharmacovigilance systems.

\section{SEARCH STRATEGY}

We will search MEDLINE, PubMed, Cochrane Central Register of Controlled Trials, EMBASE, CINAHL and International Pharmaceutical Abstracts for papers describing ceftriaxone toxicity in neonates, infants, children and adolescents. The search strategy is specific for each database and includes a combination of the medical subject headings and free text terms for safety, ceftriaxone and neonates, infants and children (online supplementary appendix 1). It will include all languages. All searches will be from the beginning of the database until December 2016. We will look for additional studies in the reference lists of selected articles and contact authors for unclear information.

We will also search ADR spontaneous reporting systems to include: (1) warnings issued; (2) case reports of ADRs to ceftriaxone in children reported and (3) signal detection studies performed. The systems include WHO Pharmaceuticals Newsletter and VigiBase from WHO; FDA Drug Safety Newsletter Fact Sheet and FDA Medwatch Safety alert from America; Canadian Adverse Reaction Newsletter and Canada Vigilance Adverse Reaction Online Database from Canada; Database of Adverse Event Notifications, the Australian Adverse Drug Reactions and Medicines Safety Update from Australia; Centre for Adverse Reactions Monitoring from New Zealand; European Directorate for the Quality Medicines and European public assessment reports from Europe; Drug Safety Update, Alerts and recalls for drugs and medical devices, Safety warnings, alerts and recalls, and Safety public assessment reports from the United Kingdom and Adverse Drug Reaction Bulletin from China.

\section{STUDY RECORDS}

The literature search results will be uploaded to EndNote X7. Two reviewers will independently screen and select studies for possible inclusion in the study in two phases: title and abstracts as the first step and full text as the second step (MMH and Jiangmin). Any disagreements will be resolved by discussion and if needed a third reviewer (LNZ).

\section{RISK OF BIAS IN INDIVIDUAL STUDIES}

We will use the Cochrane risk of bias tool for RCTs and Newcastle-Ottawa Scale for case-control and cohort studies. The quality of cross-sectional study, case series and case reports will be assessed by tailored quality assessment tools developed jointly by the National Heart, Lung, and Blood Institute and Research Triangle Institute International of National Institutes of Health based on other tools from the Agency for Healthcare Research and Quality, the Cochrane Collaboration, the United States Preventive Services Task Force, the Scottish Intercollegiate Guidelines Network and the National Health Service Centre for 
Reviews and Dissemination (online supplementary appendix 2).${ }^{1622-24}$ No quality assessment will be done for reports from ADR monitoring system.

\section{DATA EXTRACTION}

Data will be extracted from all included studies using specifically developed data extraction forms. Extracted information will include: study information (study ID, citation, country, institution, contact information), confirmation of eligibility for review, method (study design, information of study quality according to quality assessment criteria of different types of studies), participant and setting (sample size, inclusion criteria, diagnostic criteria, setting), intervention (medicine, route, dose), outcomes (type and severity of ADRs) and conclusion (authors' conclusion on safety evaluation). For continuous data, mean, SD and number of participants will be extracted. For categorical data, events and total number of participants will be extracted. Whenever possible, we will use the results from an intention-to-treat analysis. The author of the included studies will be contacted, when necessary, to gather relevant information.

\section{DATA ANALYSIS AND SYNTHESIS Strategy for data synthesis}

Relative risks will be measured in RCTs and cohort studies, ORs in case-control studies and reporting ORs in ADR spontaneous reporting systems. ${ }^{25}{ }^{26}$ Only ADRs identified from two or more studies will be analysed. The relative risks of ADRs present in at least two RCTs and cohort studies will be calculated, and only the $R R>1$ with at least three cases will be included suggesting that more ADRs were associated with ceftriaxone. Meta-analysis of the RCTs will be done using Revman. The data will be considered homogeneous if $\mathrm{I}^{2} \leq 50 \%$. Homogeneous data will be analysed using the fixed-effect model, whereas heterogeneous data will be analysed using the random-effect model. The incidence of total ADRs and severe ADRs will be assessed separately. The $\chi^{2}$ test will be used to compare cases. P-values $<0.05$ will be considered statistically significant for all analyses.

\section{Subgroup analyses}

Subgroup analyses or, if applicable, metaregression analyses will be performed for factors presumed to cause variations in outcomes including age and dosage regimen (total dosage and total course).

\section{ETHICS AND DISSEMINATION}

The result of this systematic review will be disseminated by publication in a peer-reviewed journal. Ethical assessment is not needed because we will search and evaluate only existing sources of literature. Our findings should be of benefit to health professionals who prescribe ceftriaxone.

Contributors LNZ designed and wrote the review protocol. IC provided the idea of the topic and revised the manuscript. LLZ revised the manuscript and will coordinate the review process. SX contributed to the design of the search strategy and will contribute to data collection and analysis. MMH contributed to the design of the statistical methods and will contribute to data collection and analysis. ZC produced the initial draft of the manuscript in conjunction with LNZ. All authors read, provided feedback and approved the final manuscript.

Funding This paper was supported by the National Science Foundation for Young Scholars of China (no 71503177) and the Natural Science Foundation of China (no 81373381).

\section{Competing interests None declared.}

Provenance and peer review Not commissioned; externally peer reviewed.

Open Access This is an Open Access article distributed in accordance with the Creative Commons Attribution Non Commercial (CC BY-NC 4.0) license, which permits others to distribute, remix, adapt, build upon this work non-commercially, and license their derivative works on different terms, provided the original work is properly cited and the use is non-commercial. See: http://creativecommons.org/ licenses/by-nc/4.0/

(c) Article author(s) (or their employer(s) unless otherwise stated in the text of the article) 2017. All rights reserved. No commercial use is permitted unless otherwise expressly granted.

\section{REFERENCES}

1. Food and drug administration. Intravenous ceftriaxone (Marketed as Rocephin and Generics) and calcium Drug-Drug interaction: potential risk for Cardiovascular adverse events in neonates. FDA Drug Safety Newsletter 2009;2 http://www.fda.gov/drugs/drugsafety/ drugsafetynewsletter/ucm189806.htm\#IntravenousCeftriaxoneMa rketedasRocephinandGenericsandCalciumDrug-DrugInteraction: PotentialRiskforCardiovascularAdverseEventsinNeonates.

2. Richards DM, Heel RC, Brogden RN, et al. Ceftriaxone. A review of its antibacterial activity, pharmacological properties and therapeutic use. Drugs 1984;27:469-527.

3. Blumer J. Pharmacokinetics of ceftriaxone. Hosp Pract 1991;26 Suppl 5:7-13.

4. Cleeland R, Squires E. Antimicrobial activity of ceftriaxone: a review. AMJMED 1984;77:3-11.

5. McCracken GH, Siegel JD, Threlkeld N, et al. Ceftriaxone pharmacokinetics in newborn infants. Antimicrob Agents Chemother 1983;23:341-3.

6. Van Reempts PJ, Van Overmeire B, Mahieu LM, et al. Clinical experience with ceftriaxone treatment in the neonate. Chemotherapy 1995; 41:316-22.

7. Girgis NI, Sultan Y, Hammad O, et al. Comparison of the efficacy, safety and cost of cefixime, ceftriaxone and aztreonam in the treatment of multidrug-resistant Salmonella typhi septicemia in children. Pediatr Infect Dis J 1995;14:603-5.

8. Food and drug administration. Information for Healthcare Professionals: Ceftriaxone. 2007;9 http://www.fda.gov/Drugs/ DrugSafety/PostmarketDrugSafetylnformationforPatientsandProvi ders/DrugSafetylnformationforHeathcareProfessionals/ucm134328. htm.

9. FDA. Intravenous ceftriaxone (Marketed as Rocephin and Generics) and calcium Drug-Drug interaction: potential risk for Cardiovascular adverse events in neonates. Postmarket Reviews. 2009:2 3 http:// www.fda.gov/drugs/drugsafety/drugsafetynewsletter/ucm189806. $\mathrm{htm \# IntravenousCeftriaxoneMarketedasRocephinandGenericsan}$ dCalciumDrug-DrugInteraction:PotentialRiskforCardiovascular AdverseEventsinNeonates (accessed 9 Jan 2017).

10. Yao $Y$, Zhou $R$, Wang $Y$. Fatal adverse effects of injected ceftriaxone sodium in China. Pharmacoepidemiol Drug Saf 2012;21:1197-201.

11. Otunctemur A, Ozbek E, Polat EC, et al. Increasing urinary calcium excretion after ceftriaxone and cephalothin therapy in adults: possible association with urolithiasis. Urolithiasis 2014;42:105-8.

12. Potential signals of Serious risks/New Safety Information Identified from the adverse event Reporting System (AERS) between January - March. 2009 http://www.fda.gov/drugs/ guidancecomplianceregulatoryinformation/surveillance/adversedru geffects/ucm185260.htm (accessed 9 Jan 2017). 
13. Ferrajolo C, Verhamme KM, Trifirò G, et al. Antibiotic-Induced liver Injury in Paediatric Outpatients: a Case-Control Study in primary care databases. Drug Saf 2017;40:305-15.

14. Northrop MS, Agarwal HS. Ceftriaxone-induced hemolytic anemia: case report and review of literature. J Pediatr Hematol Oncol 2015;37:63-6.

15. Donnelly PC, Sutich RM, Easton R, et al. Ceftriaxone-Associated biliary and Cardiopulmonary adverse events in neonates: a systematic review of the Literature. Paediatr Drugs 2017;19:21-34.

16. Higgins J, Green S. Cochrane handbook for systematic reviews of interventions. Chichester, UK: The Cochrane Library,John Wiley \& Sons, 2011.

17. Moher D, Liberati A, Tetzlaff J, et al. Preferred reporting items for systematic reviews and meta-analyses: the PRISMA statement. BMJ 2009;339:b2535-35.

18. The International Conference on Harmonization of Technical Requirements for Registration of Pharmaceuticals for Human Use. Guidance for industry E11 clinical investigation of Medicinal Products in the Pediatric Population. 2000 http://www.fda.gov/cder/guidance/ index.htm (accessed 9 Jan 2017).

19. The UPPSALA monitoring centre. The use of the WHO-UMC system for standardized case causality assessment. http://who-umc.org/ Graphics/24734.pdf (accessed 9 Jan 2017).
20. Egunsola O, Choonara I, Sammons HM. Safety of lamotrigine in paediatrics: a systematic review. BMJ Open 2015;5:e007711.

21. Egunsola O, Choonara I, Sammons HM. Safety of Levetiracetam in Paediatrics: a systematic review. PLoS One 2016;11:e0149686.

22. Wells GA, Shea B, O'Connell D, et al. The Newcastle-Ottawa Scale (NOS) for assessing the quality if nonrandomized studies in metaanalyses. http://www.ohri.ca/ programs/clinical_epidemiology/ oxford.htm (accessed 9 Jan 2017).

23. National Heart, Lung and Blood Institute. Quality Assessment Tool for Observational Cohort and Cross-Sectional Studies. https://www. nhlbi.nih. gov/health-pro/guidelines/in-develop/cardiovascular-riskreduction/tools/cohort (accessed 9 Jan 2017).

24. National Heart, Lung and Blood Institute. Quality Assessment Tool for Case Series Studies. https://www.nhlbi.nih.gov/health-pro/ guidelines/in- develop/cardiovascular-risk-reduction/tools/case_ series (accessed 9 Jan 2017).

25. van Puijenbroek EP, Egberts AC, Meyboom RH, et al. Different risks for NSAID-induced anaphylaxis. Ann Pharmacother 2002;36:24-9.

26. Rothman KJ, Lanes S, Sacks ST. The reporting odds ratio and its advantages over the proportional reporting ratio. Pharmacoepidemiol Drug Saf 2004;13:519-23. 